\title{
Sensorless Variable Speed Single-Phase Induction Motor Drive System Based on Direct Rotor Flux Orientation
}

\author{
M. Caruso*,V. Cecconi*,A.O. Di Tommaso*, R. Rocha ${ }^{\dagger}$ \\ * Department of Electrical, Electronic, Telecommunications and Automation Engineering \\ University of Palermo \\ Vialle delle Scienze, Ed. 9, 90128, Palermo, Italia \\ E-mail: maxcar1979@unipa.it,vittorio.cecconi@unipa.it,ditommaso@dieet.unipa.it \\ ${ }^{\dagger}$ Department of Control and Automation Engineering, School of Mines, \\ Federal University of Ouro Preto \\ Campus Morro do Cruzeiro, 35400-000, Ouro Preto, Minas Gerais, Brazil \\ E-mail: rocha@em.ufop.br
}

\begin{abstract}
The single-phase induction motor (SPIM) is one of the electrical machines more used in the World, and can be found in several fractional and sub-fractional horsepower applications in houses, offices, shoppings, farms, and industries. The introduction of more sophisticated applications has required the use of variable speed drives for SPIM, where the adoption of sensorless techniques is the more reasonable option for speed control due to the low cost of this electrical machine. A proposal for sensorless variable speed SPIM drive based on direct rotor field orientation techniques is presented in this paper. None transformation is used in order to eliminate the asymmetry of the stator windings of the SPIM. The rotor speed is estimated from an flux observer, which is based on two independent linear feedback control systems. The speed and flux estimatives are used in two control loop based on PID regulators, which determine the voltages to be applied to the SPIM windings by a three-legs VSI inverter. Using computer simulations, two situations are considered in order to demonstrate the satisfactory performance of the proposed sensorless speed control for SPIM drives: variations on rotor speed reference and the application of mechanical load.
\end{abstract}

Index Terms-Sensorless, Variable Speed Drives, Single-Phase Induction Motor, Direct Field Orientation.

\section{INTRODUCTION}

The single-phase induction motor (SPIM) is one of the more used machines in the World, and can be found in several fractional and sub-fractional horsepower applications such as air conditioning systems, mixers, washers, blowers, dryers, fans, refrigerators, vacuum cleaners, compressors, pumps, etc. A SPIM is basically an unbalanced electrical machine constituted by a squirrel-cage rotor and two asymmetrical stator windings, which have different impedances and are spatially displaced $90^{\circ}$. When this electrical machine is fed by a single-phase power source, a pulsating and stationary magnetic field is produced by the main winding, while the the auxiliary winding must emulate a second phase in order to provide the start-up torque. Usually connected with a series capacitor, the auxiliary winding is often switched off by a centrifugal switch when the
SPIM rotor reaches $60 \%$ to $80 \%$ of rated speed, although it can be maintained at running operation in order to obtain a higher and less pulsating torque.

The introduction of more sophisticated applications and the cost reduction of the static power converters have stimulated the search for an optimized operation with high performance for the SPIM. Many proposals to improve the SPIM performance are based in the use of an electronically switched series capacitor in the auxiliary winding, which can be controlled to improve the machine performance at different operating conditions [1], [2], [3], [4]. Considering the use of variable speed drives, the most of the control techniques for the SPIM drive are based on the use of constant $\mathrm{V} / \mathrm{F}$ relation, phasor, or on vectorial control with field orientation, usually utilizing appropriate transformations in order to eliminate the asymmetry of the stator windings [6], [5], [7], [8], [9], [10], [11], [12], [13], [14]. Sensorless techniques is the more reasonable option for the control of fractional and low cost SPIM applications, since the small size and low cost of this motor does not justify the use of speed sensors due to reduction of reliability and increase of complexity, cost, difficulties, weight, size, and electrical susceptibility. Some approaches have been suggested for sensorless control of SPIM drives, where the rotor speed estimation are usually obtained from the machine model and the measurements of stator voltages and currents [4], [10], [13], [15], [16], [17].

A proposal for sensorless variable speed SPIM drive based on direct rotor field orientation techniques is presented in this paper. None transformation is used in order to eliminate the asymmetry of the stator windings of the SPIM. The rotor speed is estimated from an flux observer, which is based on two independent linear feedback control systems. The speed and flux estimatives are used in two control loop based on PID regulators, which determine the voltages to be applied to the SPIM windings by a three-legs VSI inverter. Using computer simulations, two situations are considered in order 
to demonstrate the satisfactory performance of the proposed sensorless speed control for SPIM drives: variations on rotor speed reference and the application of mechanical load.

\section{Dynamic Model of THE SPIM}

Traditionally, the dynamic model of a SPIM is described considering a stationary reference frame $\alpha \beta$ fixed in the stator, where $\alpha$ and $\beta$ respectively denote the auxiliary and main windings [18]. Considering all rotor variables referred to the stator windings, the dynamic voltage equations of SPIMs are given by

$$
\begin{aligned}
& \dot{\lambda}_{s \alpha}=v_{s \alpha}-R_{s \alpha} i_{s \alpha}, \\
& \dot{\lambda}_{s \beta}=v_{s \beta}-R_{s \beta} i_{s \beta}, \\
& \dot{\lambda}_{r \alpha}=v_{r \alpha}-R_{r \alpha} i_{r \alpha}-N \omega_{r} \lambda_{r \beta}, \\
& \dot{\lambda}_{r \beta}=v_{r \beta}-R_{r \beta} i_{r \beta}+\frac{\omega_{r} \lambda_{r \alpha}}{N},
\end{aligned}
$$

where $\lambda=$ flux, $i=$ current, $v=$ voltage, $\omega=$ speed, $R=$ resistance, and $N=$ transformer ratio between both stator windings. The subscripts $s$ and $r$ are related respectively to stator and rotor variables and parameters. Since the SPIM has a squirrel-cage rotor, the rotor windings of SPIM are shortcircuited and rotor voltages $v_{r \alpha}$ and $v_{r \beta}$ are null. The flux equations are

$$
\begin{aligned}
& \lambda_{s \alpha}=L_{s \alpha} i_{s \alpha}+L_{m \alpha}\left(i_{s \alpha}+i_{r \alpha}\right), \\
& \lambda_{s \beta}=L_{s \beta} i_{s \beta}+L_{m \beta}\left(i_{s \beta}+i_{r \beta}\right), \\
& \lambda_{r \alpha}=L_{r \alpha} i_{r \alpha}+L_{m \alpha}\left(i_{s \alpha}+i_{r \alpha}\right), \\
& \lambda_{r \beta}=L_{r \beta} i_{r \beta}+L_{m \beta}\left(i_{s \beta}+i_{r \beta}\right),
\end{aligned}
$$

where $L=$ winding inductance and $L_{m}=$ mutual inductance. The instantaneous electromagnetic torque $T_{e}$ can be expressed by

$$
T_{e}=N \frac{P}{2}\left(L_{m \beta} i_{s \beta} i_{r \alpha}-L_{m \alpha} i_{s \alpha} i_{r \beta}\right) .
$$

\section{FLuX OBSERVER}

If the stator currents $i_{s}$ and the rotor flux $\lambda_{r}$ vectors are admitted as the state variables, this dynamic model can be written as:

- $\alpha$-model

$\dot{i}_{s \alpha}=\frac{L_{m \alpha}}{L_{\sigma \alpha}}\left(\frac{L_{r \alpha}}{L_{m \alpha}} v_{s \alpha}+\frac{R_{r \alpha}}{L_{r \alpha}} \lambda_{r \alpha}-\frac{R_{\phi \alpha}}{L_{r \alpha} L_{m \alpha}} i_{s \alpha}+\frac{u_{\alpha}}{N}\right)$,

$\dot{\lambda}_{r \alpha}=-\frac{R_{r \alpha}}{L_{r \alpha}}\left(\lambda_{r \alpha}-L_{m \alpha} i_{s \alpha}\right)-\frac{u_{\alpha}}{N}$,

- $\beta$-model

$\dot{i}_{s \beta}=\frac{L_{m \beta}}{L_{\sigma \beta}}\left(\frac{L_{r \beta}}{L_{m \beta}} v_{s \beta}+\frac{R_{r \beta}}{L_{r \beta}} \lambda_{r \beta}-\frac{R_{\sigma \beta}}{L_{r \beta} L_{m \beta}} i_{s \beta}-N u_{\beta}\right)$,

$\dot{\lambda}_{r \beta}=-\frac{R_{r \beta}}{L_{r \beta}}\left(\lambda_{r \beta}-L_{m \beta} i_{s \beta}\right)+N u_{\beta}$,

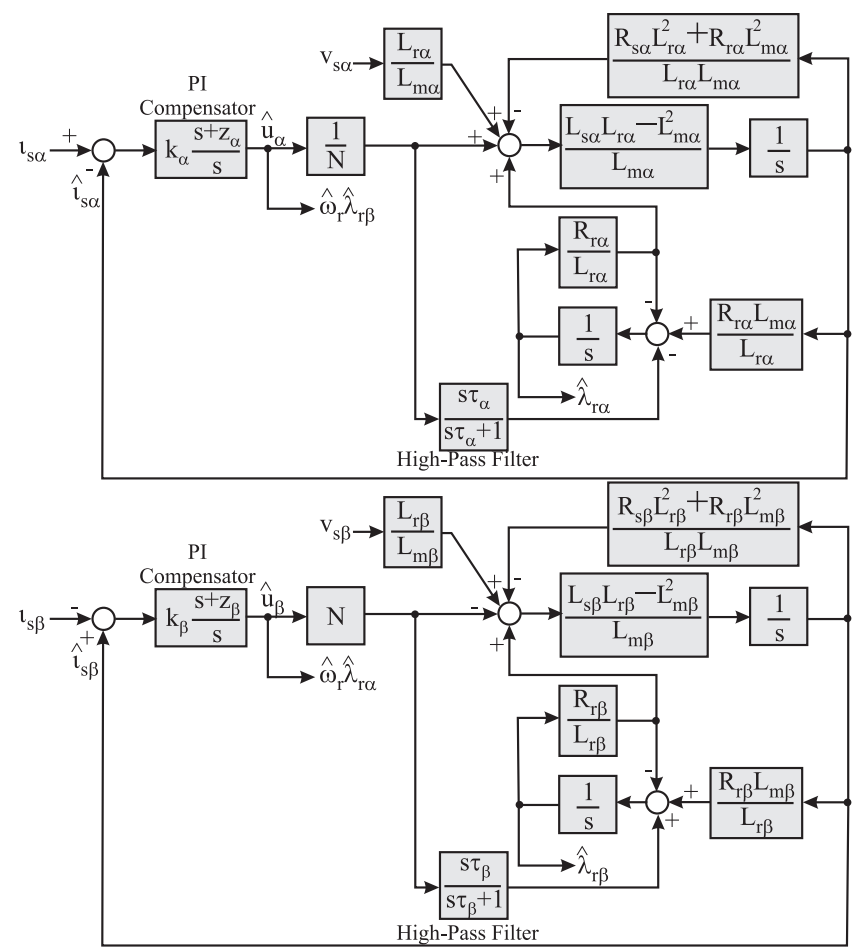

Fig. 1. Block diagram of $\alpha$ - and $\beta$-Flux observers.

where $R_{\sigma}=R_{s} L_{r}^{2}+R_{r} L_{m}^{2}$ and $L_{\sigma}=L_{s} L_{r}-L_{m}^{2}$. The $\alpha$-model is coupled to $\beta$-model by the nonlinear terms $u_{\alpha}=\omega_{r} \lambda_{r \beta}$ and $u_{\beta}=\omega_{r} \lambda_{r \alpha}$. In order to design the proposed rotor flux observer, the nonlinear terms $u_{\alpha}$ and $u_{\beta}$ are considered as the system inputs, which allows to decouple the SPIM model in two linearized and independent systems. Thus, a rotor flux observer can be designed as the two independent and linear closed-loop systems as presented in Fig. 1, where the estimative $\hat{\lambda}_{r}$ is obtained when the estimative $\hat{i}_{s}$ converges to measured stator current $i_{s}$.

Analyzing only the structure of $\alpha$-flux observer, the open loop transfer function between $\hat{i}_{s \alpha}$ and $\hat{u}_{\alpha}$ admitting $v_{s \alpha}$ as system disturbance is given by

$$
\frac{\hat{I}_{s \alpha}(s)}{\hat{U}_{\alpha}(s)}=\frac{1}{N} \frac{s L_{m \alpha}}{s^{2} L_{\sigma \alpha}+s R_{\phi \alpha}+R_{s \alpha} R_{r \alpha}},
$$

where $R_{\phi \alpha}=R_{r \alpha} L_{s \alpha}+R_{s \alpha} L_{r \alpha}$. This transfer function presents a zero in the origin, which provides a derivative action that increases the observer sensitivity to noises and disturbances and does not contribute to reduce the current error. In order to eliminate the effects of the derivative action of $\alpha$-model, a PI structure is considered for $\alpha$-compensator

$$
\frac{\hat{U}_{\alpha}(s)}{\hat{I}_{s \alpha}(s)-I_{s \alpha}(s)}=k_{\alpha} \frac{s+z_{\alpha}}{s} \text {. }
$$

The zero $z_{\alpha}$ of the $\alpha$-compensator can be chosen to cancel the slowest pole of the open-loop transfer function of the Eq. 14 , increasing the stability range and improving the speed response of the $\alpha$-flux observer. The gain $k_{\alpha}$ determines the $\alpha$-compensator performance and can be designed in order to 


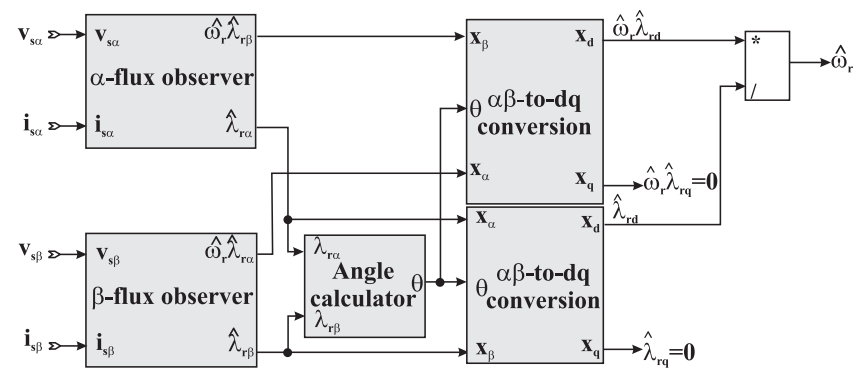

Fig. 2. Rotational speed estimation using flux observers.

increase the observer robustness, minimizing the influence of the parameter variations over the flux estimation.

Since all the systems involved in this observer (PI compensator and SPIM model) are inherently stable, the Bode criteria can be used in order to verify the stability of the proposed structure for rotor flux observation. The pole-zero canceling imposed by design of the PI compensator determines that the amplitude diagram always crosses the $0 \mathrm{~dB}$ with a slope of -20 $\mathrm{dB} / \mathrm{dec}$. In this situation, the phase in the crossover frequency is always smallest than $135^{\circ}$, which assures the stability of the rotor flux observer in a wider range.

Since PI compensator introduces a pure integrator in the close-loop transfer function of the $\alpha$-observer, a first-order high-pass filter

$$
G_{\alpha}(s)=\frac{s \tau_{\alpha}}{s \tau_{\alpha}+1} .
$$

with a very low cutoff frequency is inserted in the path of the estimated flux in order to prevent problems related to DC offset of the voltage and current sensors. Although this solution can deteriorate the dynamic performance of the proposed flux observer at very low rotor speed, it can be considered satisfactory for the speed range that a SPIM usually works. In order to reduce the effect of measurement noises in the observer performance, a first-order low-pass filter with an adequate cutoff frequency could be inserted in the measured current input to filter high frequencies signals. All principles used to analyze and design the $\alpha$-observer can be similarly applied to the $\beta$-observer.

\section{COORDINATES SYSTEM CONVERSION AND ROTOR SPEED ESTIMATION}

If the observation of the rotor fluxes is satisfactory, an estimative of the rotor speed $\hat{\omega}_{r}$ can be obtained from the proposed observer structure. In order to convert the observer outputs originally described in a stationary reference frame $\alpha \beta$ fixed in the stator into rotating $d q$-coordinates aligned to flux vector, the $\alpha \beta$-to- $d q$ transformation given by

$$
\begin{gathered}
x_{d}=x_{\alpha} \cos \theta+x_{\beta} \sin \theta, \\
x_{q}=-x_{\alpha} \sin \theta+x_{\beta} \cos \theta,
\end{gathered}
$$

where the trigonometric functions are

$$
\sin \theta=\frac{\hat{\lambda}_{r \beta}}{\sqrt{\hat{\lambda}_{r \alpha}^{2}+\hat{\lambda}_{r \beta}^{2}}},
$$

$$
\cos \theta=\frac{\hat{\lambda}_{r \alpha}}{\sqrt{\hat{\lambda}_{r \alpha}^{2}+\hat{\lambda}_{r \beta}^{2}}},
$$

is applied as presented in the Fig. 2. The orthogonal components $\hat{\lambda}_{r q}$ and $\hat{u}_{d}$ are null, while the direct components $\hat{\lambda}_{r d}$ and $\hat{u}_{q}$ correspond to estimated rotor flux vector $\hat{\lambda}_{r}$ and nonlinear term $\hat{\omega}_{r} \hat{\lambda}_{r}$. Thus, the rotor speed $\hat{\omega}_{r}$ can be estimated as

$$
\hat{\omega}_{r}=\frac{\hat{u}_{q}}{\hat{\lambda}_{r d}} .
$$

\section{ROTOR FLUX REGULATION AND ROTOR SPEED CONTROL}

Since the variables are described in rotating $d q$-coordinates system aligned to the flux vector, vectorial techniques can be used in the control of the SPIM drive. A PI regulator can determine the direct current component $i_{s d}$ in order to regulate the rotor flux

$$
I_{s d}=k_{p \lambda} \frac{s+z_{\lambda}}{s}\left(\Lambda_{r e f}-\hat{\Lambda}_{r}\right),
$$

where the zero $z_{\lambda}$ could eliminate the slowest pole of the flux open-loop transfer function. The electromagnetic torque is controlled using the orthogonal current component $i_{s q}$ established by a PI regulator

$$
I_{s q}=k_{p \omega} \frac{s+z_{\omega}}{s}\left(\Omega_{r e f}-\hat{\Omega}_{r}\right),
$$

whose the zero $z_{\omega}$ is chosen to cancel the slowest pole of the mechanical open-loop transfer function.

Using the eqs. 10 and 12 , the stator voltages $v_{s d}$ and $v_{s q}$ can be obtained from the stator currents $i_{s d}$ and $i_{s q}$ as:

$$
\begin{gathered}
V_{s d}=k_{p v s \alpha}\left(s+z_{v s \alpha}\right) I_{s d}-\frac{R_{r \alpha} L_{m \alpha}}{L_{r \alpha}^{2}} \hat{\Lambda}_{r}, \\
V_{s q}=k_{p v s \beta}\left(s+z_{v s \beta}\right) I_{s q}+N \frac{L_{m \beta}}{L_{r \beta}} \hat{U}_{q},
\end{gathered}
$$

where

$$
\begin{gathered}
k_{p v s}=\frac{L_{\sigma}}{L_{r}}, \\
z_{v s}=\frac{R_{\sigma}}{L_{r} L_{\sigma}} .
\end{gathered}
$$

From the insertion of the eqs. 22 and 23 in the eqs. 24 and 25 ,

$$
\begin{gathered}
V_{s d}=k_{p d} \frac{\left(s+z_{v s \alpha}\right)\left(s+z_{\lambda}\right)}{s}\left(\Lambda_{r e f}-\hat{\Lambda}_{r}\right)-\frac{R_{r \alpha} L_{m \alpha}}{L_{r \alpha}^{2}} \hat{\Lambda}_{r}, \\
V_{s q}=k_{p q} \frac{\left(s+z_{v s \beta}\right)\left(s+z_{\omega}\right)}{s}\left(\Omega_{r e f}-\hat{\Omega}_{r}\right)+N \frac{L_{m \beta}}{L_{r \beta}} \hat{U}_{q},
\end{gathered}
$$

and the original PI regulators are converted into PID controllers in whose outputs are added feed-forward terms to determine the stator voltage components, as shown in the Fig. 3. Eventually, if the zero $z_{v s \beta}$ is significantly greatest than the zero $z_{w}$, the derivative action introduced by the voltage equation can be neglected since its influence over the control system tends to quickly extinguished, and a simple PI regulator could be used in the speed close-loop control structure. The 


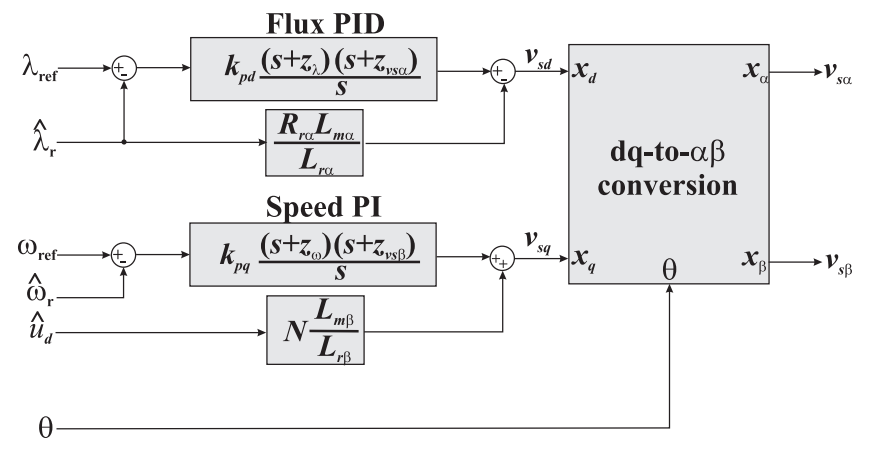

Fig. 3. Block diagram for flux and speed control.

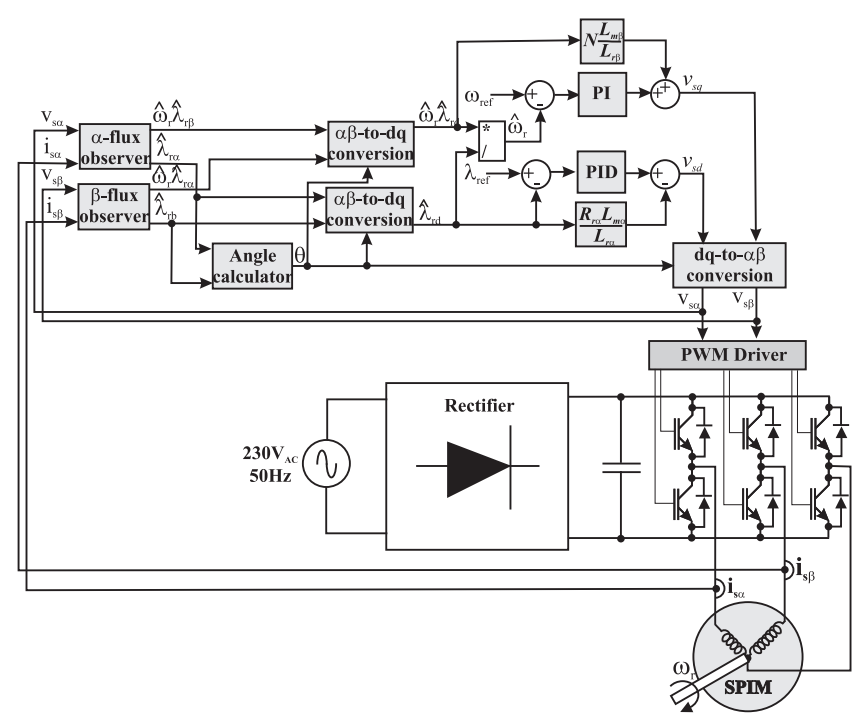

Fig. 4. Proposed sensorless variable speed drive for SPIM

rotating $d q$ voltage components are converted into stationary reference frame $\alpha \beta$ fixed in the stator in order to obtain the voltages $v_{s \alpha}$ and $v_{s \beta}$ to be applied in the SPIM drive.

\section{Simulation RESUlts}

The proposed sensorless scheme for variable speed drive for SPIM is shown in Fig. 4, and its performance is verified from computational simulations considering the data presented in table I. It is considered that the SPIM windings are fed by two quadrature AC voltages generated by an three-leg voltage source inverter, a configuration that presents many advantages over the two-leg topology such as the generation of a zero voltage vector, without circulation of AC current in the DC link capacitor, and a better quality of the output voltage in terms of harmonic distortion [13], [19], [20], [21], [22], [23].

The drive response to variations on speed reference $\omega_{\text {ref }}$ and to application of mechanical load is shown in Fig. 5. Firstly, the unloaded SPIM is started and accelerated to $2 \pi 50$ $\mathrm{rad} / \mathrm{s}$ and, after $1 \mathrm{~s}$, a mechanical load of $1 \mathrm{~N} / \mathrm{m}$ is applied to machine shaft. The application of the mechanical load causes a little drop in the speed rotor $\omega_{r}$, increasing the error in the speed regulation. The rotor speed is reduced to $2 \pi 15 \mathrm{rad} / \mathrm{s}$ at $2 \mathrm{~s}$, and at $3 \mathrm{~s}$ the machine is again accelerated to $2 \pi 25 \mathrm{rad} / \mathrm{s}$.
TABLE I

SPIM DATA

\begin{tabular}{|c|c|c|c|}
\hline \multicolumn{4}{|c|}{ Rated values } \\
\hline \multicolumn{2}{|r|}{ Voltage } & \multicolumn{2}{|r|}{$110 \mathrm{~V}$} \\
\hline \multicolumn{2}{|r|}{ Frequency } & \multicolumn{2}{|r|}{$50 / 60 \mathrm{~Hz}$} \\
\hline \multicolumn{2}{|r|}{ Speed } & \multicolumn{2}{|r|}{2700 RPM } \\
\hline \multicolumn{2}{|r|}{ Nr. of poles } & \multicolumn{2}{|r|}{2} \\
\hline \multicolumn{2}{|r|}{ Power } & \multicolumn{2}{|c|}{$0.25 \mathrm{HP}(180 \mathrm{~W})$} \\
\hline \multicolumn{2}{|c|}{ Main winding $(\beta)$} & \multicolumn{2}{|c|}{ Auxiliary winding $(\alpha)$} \\
\hline$R_{s \beta}$ & $5.2 \Omega$ & $R_{s \alpha}$ & $29 \Omega$ \\
\hline$R_{r \beta}$ & $9.4 \Omega$ & $R_{r \alpha}$ & $35.9 \Omega$ \\
\hline$L_{m \beta}$ & $0.3 \mathrm{H}$ & $L_{m \alpha}$ & $0.45 \mathrm{H}$ \\
\hline$L_{s \beta}$ & $0.3068 \mathrm{H}$ & $L_{s \alpha}$ & $0.55 \mathrm{H}$ \\
\hline$L_{r \beta}$ & $0.3068 \mathrm{H}$ & $L_{r \alpha}$ & $0.55 \mathrm{H}$ \\
\hline \multicolumn{2}{|c|}{ N $N=N_{\beta} / N_{\alpha}$} & \multicolumn{2}{|r|}{0.67} \\
\hline \multicolumn{4}{|c|}{ Mechanical Parameters } \\
\hline$J$ & $0.00145 \mathrm{~kg} \cdot \mathrm{m}^{2}$ & $B$ & $0.00027 \mathrm{~kg} . \mathrm{m} / \mathrm{s}$ \\
\hline \multicolumn{4}{|c|}{$\overline{\text { Observer compensator }}$} \\
\hline \multicolumn{4}{|c|}{$\alpha$-compensator } \\
\hline $\mathrm{P}$ & 7000 & I & 224000 \\
\hline \multicolumn{4}{|c|}{$\beta$-compensator } \\
\hline $\mathrm{P}$ & 7500 & $\mathrm{I}$ & 82500 \\
\hline \multicolumn{4}{|c|}{ Controller } \\
\hline \multicolumn{4}{|c|}{ Flux PID regulator } \\
\hline \multirow[t]{2}{*}{$\mathrm{P}$} & 4669 & $\mathrm{I}$ & 248200 \\
\hline & & $\mathrm{D}$ & 13.09 \\
\hline \multicolumn{4}{|c|}{ Speed PID regulator } \\
\hline $\bar{P}$ & 15 & $\mathrm{I}$ & 2.838 \\
\hline & & $\mathrm{D}$ & 0 \\
\hline
\end{tabular}

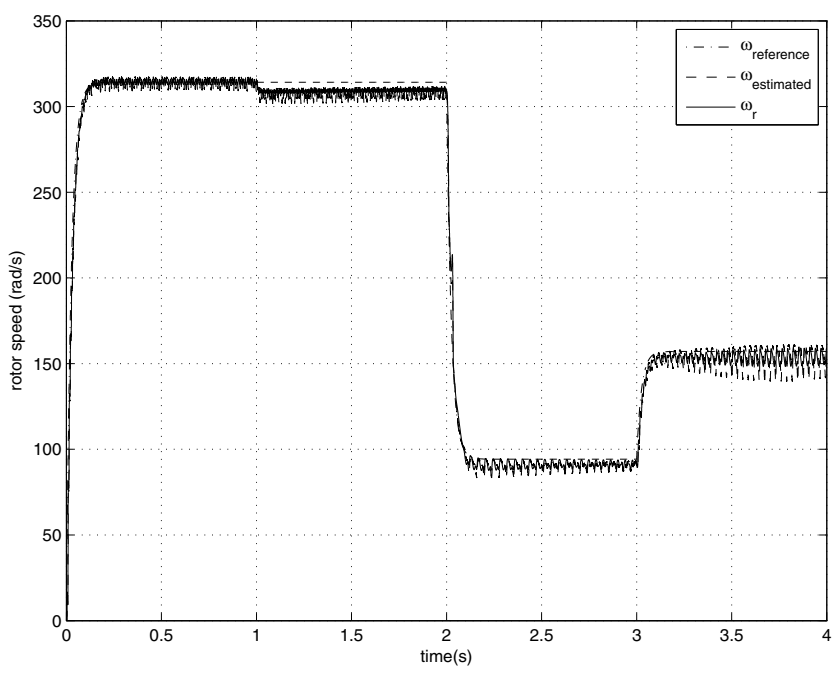

Fig. 5. Rotor speed response considering variations on the reference $\omega_{\text {ref }}$ and the application of mechanical load.

It is observed that the estimation of the rotor speed is accurate and the speed control presents a good performance, since $\omega_{r}$ follows the reference $\omega_{\text {ref }}$ with an error smallest than $3 \%$. The electromagnetic torque is oscillatory and presents a fast response as can observed in Fig. 6.

The rotor flux $\lambda_{r}$ presents a circular profile and the load variation does not affect the flux regulation, as shown in the Fig. 7, where is observed that the amplitude of the rotor flux 


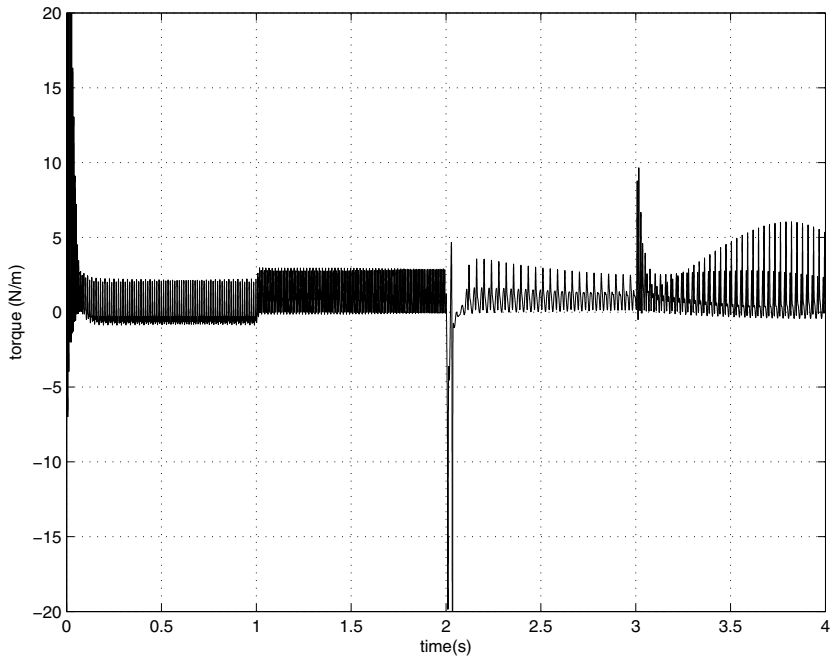

Fig. 6. Electromagnetic torque response considering variations on the reference $\omega_{\text {ref }}$ and the application of mechanical load.

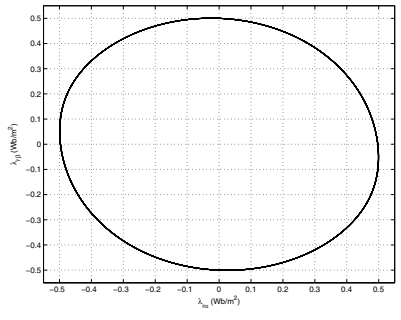

(a) Time: $0.5 \mathrm{~s}$ to $0.8 \mathrm{~s}$

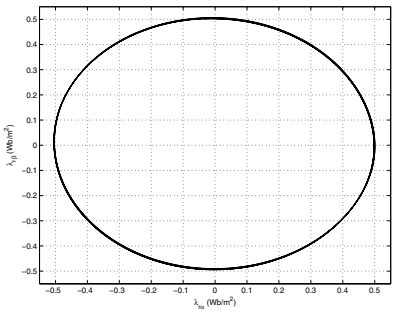

(c) Time: $2.5 \mathrm{~s}$ to $2.8 \mathrm{~s}$

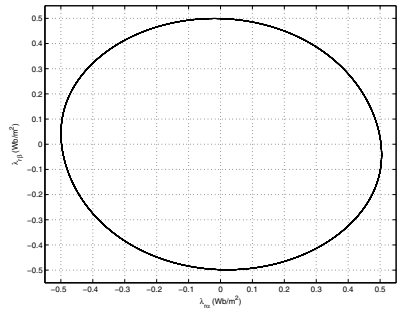

(b) Time: $1.2 \mathrm{~s}$ to $1.5 \mathrm{~s}$

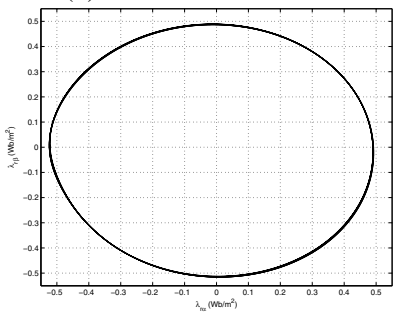

(d) Time: $3.5 \mathrm{~s}$ to $3.8 \mathrm{~s}$
Fig. 7. Phase portrait of rotor flux vector $\lambda_{r \alpha} \times \lambda_{r \beta}$ at four moments: (a) unloaded SPIM at $\omega_{r}=2 \pi 50 \mathrm{rad} / \mathrm{s}$, (b) loaded SPIM at $\omega_{r}=2 \pi 50 \mathrm{rad} / \mathrm{s}$, (c) loaded SPIM at $\omega_{r}=2 \pi 15 \mathrm{rad} / \mathrm{s}$, (d) loaded SPIM at $\omega_{r}=2 \pi 25 \mathrm{rad} / \mathrm{s}$.

$\lambda_{r}$ is practically maintained constant by the control system in $0.5 \mathrm{~Wb} / \mathrm{m}^{2}$. However, a circular profile for the rotor flux implies in a harmonic content in the stator currents in order to compensate the unbalance in this machine, as shown the Fig. 8. The amplitude of the main current $i_{s \beta}$ increases with the mechanical load while the amplitude of the auxiliary current $i_{s \alpha}$ is slightly reduced. The rotor speed variations imply in greatest amplitude variations of the main current $i_{s \beta}$ than of the auxiliary current $i_{s \alpha}$.

\section{CONCLUSION}

A proposal for sensorless variable speed SPIM drive based on direct rotor field orientation techniques is presented in this paper. An observer based on two independent linear closed-loop control systems provides the flux $\hat{\lambda}_{r}$ and speed $\hat{\omega}_{r}$ estimatives of the SPIM. The variables are converted into rotating $d q$ coordinates, where the $d$-axis is aligned to flux vector. Thus, the direct component $i_{s d}$ regulates the rotor flux $\lambda_{r}$, while the electromagnetic torque $T_{e}$ is controlled using the orthogonal component $i_{s q}$. The $d q$ stator voltage components are determined two PID regulators, whose outputs are added feed-forward terms, and converted into stationary reference frame fixed in the stator in order to obtain the $\alpha \beta$ stator voltage components to be applied in the SPIM windings by a three-legs VSI inverter. From computer simulations, it is observed that the proposed sensorless variable speed drive for SPIM presents a good accuracy in the estimation of the $\lambda_{r}$ and $\omega_{r}$, and a good performance in the flux regulation and speed control. Since none variable transformation is applied in order to eliminate the asymmetry of the stator windings of the SPIM, a circular profile is obtained for the rotor flux vector. The result is the presence of a harmonic content in the stator currents in order to compensate this asymmetry. The increase of the mechanical load does not affect the flux regulation, but it causes a little drop in the speed rotor $\omega_{r}$ and a increase in the error of the speed control. The amplitude of the main current $i_{s \beta}$ increases with the mechanical load, while the amplitude of the auxiliary current $i_{s \alpha}$ is slightly reduced. Since the performance of the proposed sensorless variable speed drive for SPIM is satisfactory, it can consist in an interesting option for SPIM applications that requires variable speed drives. The experimental performance of the proposed sensorless variable speed drive for SPIM will be included in a future paper.

\section{ACKNOWLEDGMENT}

The authors gratefully thank SDESLab (Sustainable Development and Energy Savings Laboratory) - University of Palermo - for the support given during the experimental tests, and the financial support of MIUR (Ministero dell'Istruzione dell'Universitá e della Ricerca - Italia), CNPq (Conselho Nacional de Desenvolvimento Científico e Tecnológico - Brazil), CAPES (Coordenação de Aperfeiçoamento de Pessoal de Nível Superior - Brazil), FAPEMIG (Fundação de Amparo a Pesquisa do Estado de Minas Gerais- Brazil) and Gorceix foundation (Brazil).

\section{REFERENCES}

[1] T.A. Lettenmaier, D.W. Novotny, T.A. Lipo, Single-phase induction motor with an electronically controlled capacitor, IEEE Trans. on Industry Applications, 27 (1), pp. 38 - 43, 1991.

[2] E. Mujaldi, Y. Zhao, T.-H. Liu, T.A. Lipo, Adjutable A.C. capacitor for single-phase induction motor, IEEE Trans. on Industry Applications, 29 (3), pp. 479 - 485, 1993.

[3] H.M.B. Metwally, New inverter driven design and control method for two-phase inductor motor drives, Energy Conversion and Management, 42, pp. 941 - 950, 2001.

[4] S. Vaez-Zadeh, A. Payman, Design and analysis of sensorless torque optimization for single phase induction motors, Energy Conversion and Management, 47 (11-12), pp. 1464 - 1477, 2006.

[5] E. R. Collins, Torque and slip behavior of single-phase induction motors driven from variable-frequency supplies, IEEE Transactions on Industry Application, vol. 28 (3), pp. 710 - 715, 1992.

[6] M.S.J. Asghar, Smooth speed control of single-phase induction motors by integral-cycle switching, IEEE Trans. on Energy Conversion, 14 (4), pp. 1094 - 1099, 1999. 


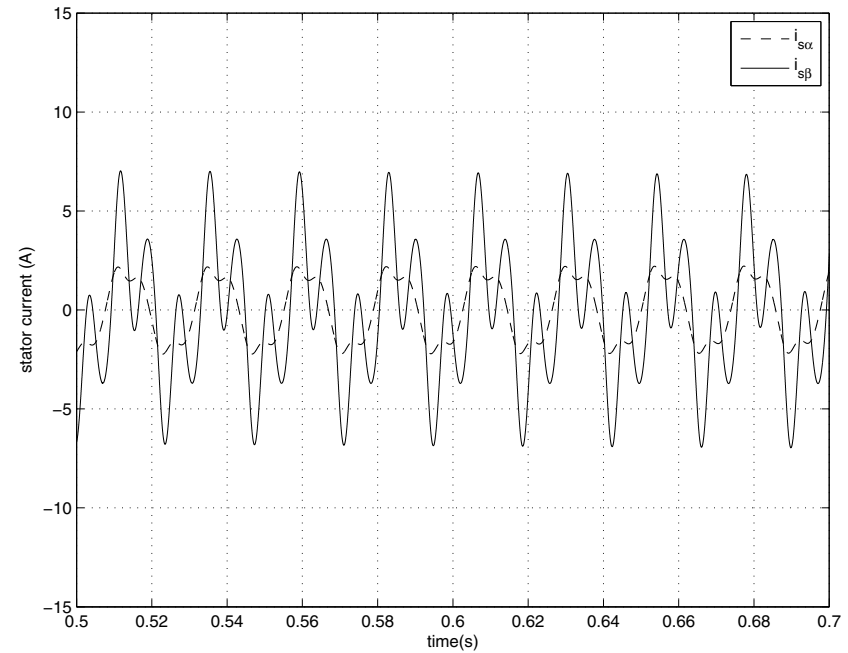

(a) $\omega_{r}=2 \pi 50 \mathrm{rad} / \mathrm{s}$ (no load)

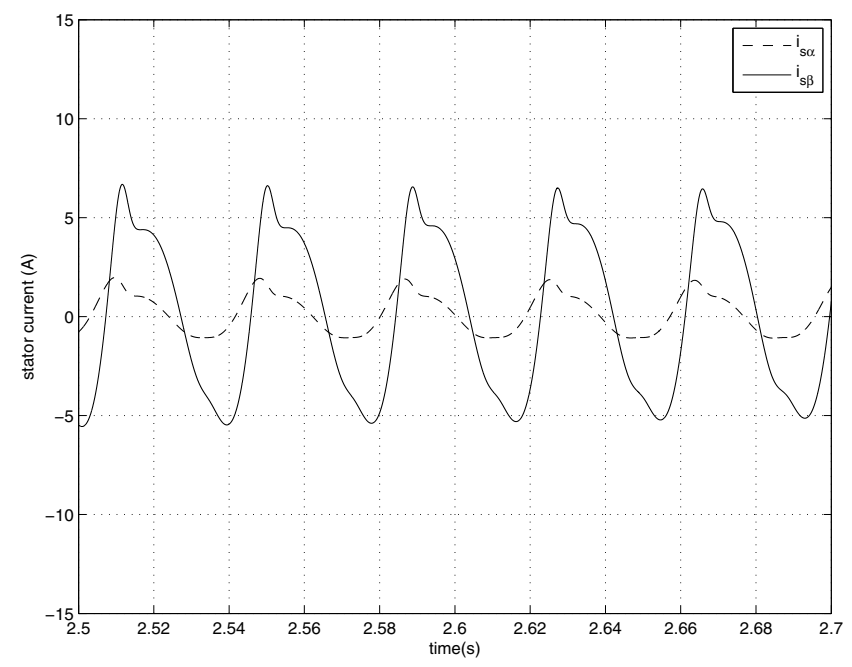

(c) $\omega_{r}=2 \pi 15 \mathrm{rad} / \mathrm{s}$

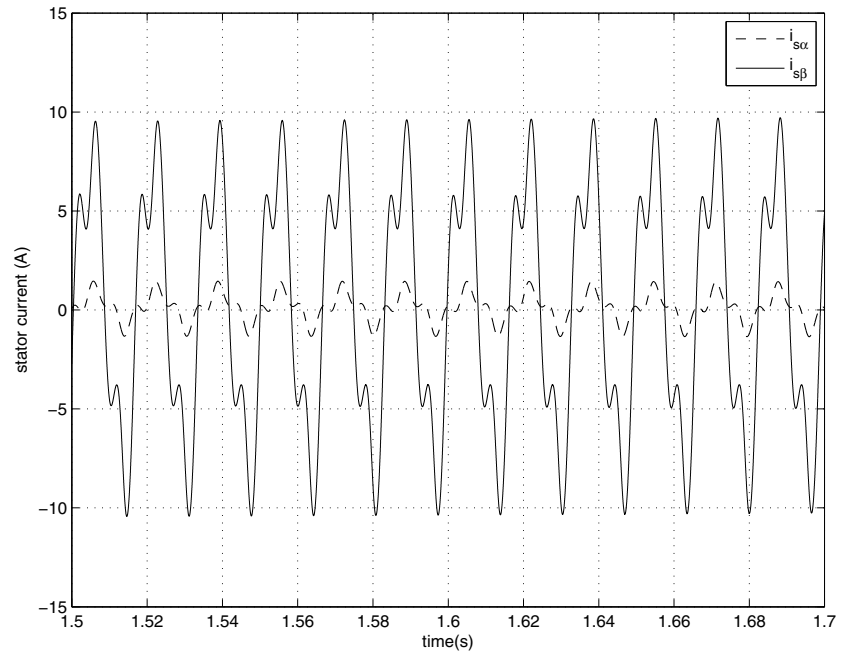

(b) $\omega_{r}=2 \pi 50 \mathrm{rad} / \mathrm{s}$

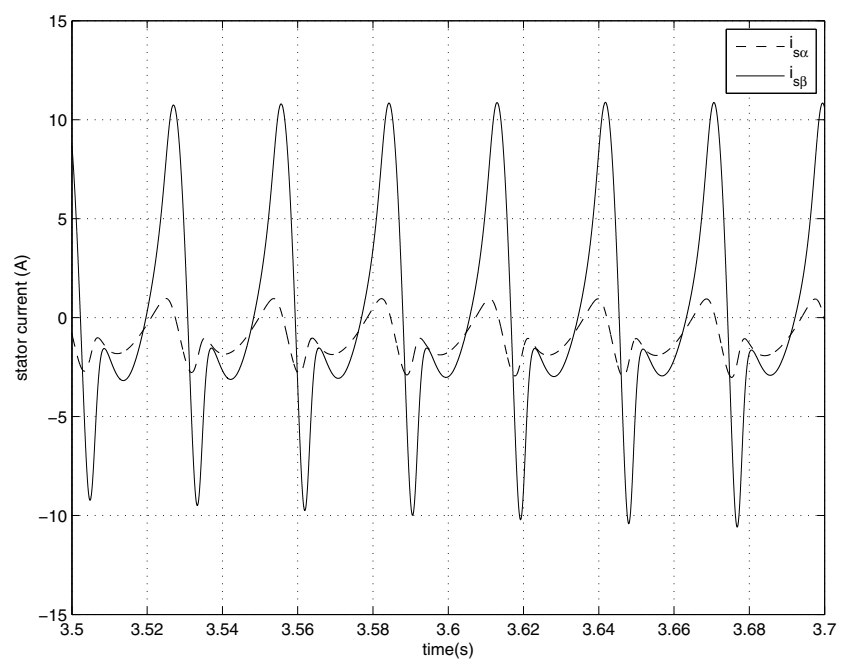

(d) $\omega_{r}=2 \pi 25 \mathrm{rad} / \mathrm{s}$

Fig. 8. Stator currents at four moments: (a) unloaded SPIM at $\omega_{r}=2 \pi 50 \mathrm{rad} / \mathrm{s}$, (b) loaded SPIM at $\omega_{r}=2 \pi 50 \mathrm{rad} / \mathrm{s}$, (c) loaded SPIM at $\omega_{r}=2 \pi 15$ $\mathrm{rad} / \mathrm{s}$, (d) loaded SPIM at $\omega_{r}=2 \pi 25 \mathrm{rad} / \mathrm{s}$.

[7] M.B. de Rossiter Corrêa, C.B. Jacobina, A.M.N. Lima, E.R.C. Silva, Rotor-flux-oriented control of a single-phase induction motor drive, IEEE Transactions on Industrial Electronics, 47 (4), 832 - 841, 2000.

[8] M.B. de Rossiter Corrêa, C.B. Jacobina, E.R.C. Silva, A.M.N. Lima, Vector control strategies for single-phase induction motor drive systems, IEEE Transactions on Industrial Electronics, 51 (5), 1073 - 1080, 2004.

[9] R. Rocha, L. S. Martins Filho, J. C. D. de Melo, A speed control for variable-speed single-phase induction motors drives, Proceedings of 2005 IEEE International Symposium on Industrial Electronics, ISIE 2005, pp. $43-48,2005$.

[10] M.B. Mohamed, M. Jemli, M. Boussak, M. Gossa, Speed sensorless vector control of single-phase induction motor, Journal of Automation \& Systems Engineering, 2 (2), 2008.

[11] M. Guerreiro, D. Foito, A. Cordeiro, A phasor speed control of a single or two phase induction motor, Proceedings of the 2008 International Conference on Electrical Machines, ICEM 2008, pp. 1 - 4, 2008.

[12] M. Jemli, H.B. Azza, M. Gossa, Real-time implementation of IRFOC for Single-Phase Induction Motor drive using dSpace DS 1104 control board, Simulation Modelling Practice and Theory, 17 (6), pp. 1071 1080, 2009.

[13] M. Jemli, H. B. Azza, M. Boussak, M. Gossa, Sensorless indirect stator field orientation speed control for single-phase induction motor drive, IEEE Transactions on Power Electronics, 24 (6), pp. 1618 - 1627, 2009.

[14] M. Guerreiro, D. Foito, A. Cordeiro, A speed controller for a two- winding induction motor based on diametrical inversion, IEEE Transactions on Industrial Electronics, 57 (1), 449 - 456, 2010.

[15] E. A. Vendrusculo, J. A. Pomilio, An adaptive speed estimator for singlephase induction motors, Proceedings of International Symposium on Power Electronics, Electrical Drives, Automation and Motion, SPEEDAM 2008, pp. 1248 - 1252, 2008.

[16] M. Caruso, V. Cecconi, A. O. Di Tommaso, R. Rocha, A flux and speed observer for sensorless SPIM applications, Proceedings of XIX International Conference on Electrical Machines, ICEM 2010, pp. 1 - 6, 2010.

[17] M. Caruso, V. Cecconi, A.O. Di Tommaso, R. Rocha, A rotor flux and speed observer for sensorless single-phase induction motor applications, International Journal of Rotating Machinery, 2012, pp. 1 - 13, 2012.

[18] P. Krause, Analysis of electric machinery, McGraw-Hill, New York, 1987.

[19] A.S. Ba-thunya, R. Khopkar, K. Wei, H.A. Toliyat, Single phase induction motor drives-a literature survey, Proceedings of 2001 IEEE International on Electric Machines and Drives Conference, IEMDC 2001, pp. $911-916,2001$.

[20] M.B. de Rossiter Corrêa, C.B. Jacobina, A.M.N. Lima, E.R.C Silva, A three-leg voltage source inverter for two-phase AC motor drive systems, IEEE Transactions on Power Electronics, 17 (4), pp. 517 - 523, June, 2002.

[21] D.-H. Jang, D.-Y. Yoon, Space-vector PWM technique for two-phase 
inverter-fed two-phase induction motors, IEEE Transaction on Industry Application, 39 (2), pp. 542 - 549, 2003.

[22] A.H. Rajaei, M. Mohamadian, S.M. Dehghan, A. Yazdian, Single-phase induction motor drive system using z-source inverter, IET Electric Power Applications, 4 (1), pp. 17 - 25, 2010.

[23] C.-M. Young, C.-C. Liu, C.-H. Liu, New inverter driven design and control method for two-phase inductor motor drives, IEE Proc. Electr. Power Appl., 143 (6), pp. 458 - 466, 1996.

Massimo Caruso received his Masters Degree in Electrical Engineering from the University of Palermo, Italy, in July 2008 and his $\mathrm{PhD}$ in Electrical Engineering from the same University in March 2012. His research fields are mainly focused on the design, simulation, microfabrication and testing of electric micromotors and their wireless power delivery systems and on the design, simulation and of control systems for electric machines. Furthermore, he also studied the influence of electromagnetic fields on biological species.

Vittorio Cecconi received the degree in Electrotechnical Engineering in 1964 at the University of Palermo. From 1965 to 1970, he was an Assistant Professor of Electrical Plants and Power Systems at the University of Palermo. In 1970 he became an Associated Professor in that department. Since 1980, he has been a Full Professor of Electrical Plants and Power Systems, teaching also Electric Machines, EMC and Electrical Measurements. His studies deal with electrical network distribution, electrical customers, electrical machines. His research is essentially experimental, dedicated to both tests and prototypical realizations.

Antonino Oscar Di Tommaso was born in Tübingen (Germany) on June 5, 1972. He received the degree in Electrical Engineering in 1999 and the $\mathrm{PhD}$ degree in 2004 from the University of Palermo, Italy. He was a post $\mathrm{PhD}$ fellow in electrical machines and drives at the Department of Electrical Engineering - University of Palermo, from 2004 to 2006. Currently he is a researcher at the Department of Electrical, Electronic and Telecommunication Engineering - University of Palermo. His main research interests deal with electrical machines, drives and power converters.

Ronilson Rocha is graduated in Electrical Industrial Engineering by Federal Center of Technological Education of Minas Gerais (1990), M.Sc. and Ph.D. in Electrical Engineering by Federal University of Minas Gerais (1995 and 2001). Currently, he is associate professor of the Federal University of Ouro Preto. He has experience in Electrical and Electronic Engineering, with emphasis in following subjects: Dynamical Systems, Control Systems, Electronic systems, Electrical Machines, Renewable Energy and Aerospace Applications. 